\title{
The Role Of The CEO, Executive Team, And Workforce Metrics Of A Small University In The U.S.
}

Pei-Chih Wei, Hsin Sheng College of Medical Care and Management, USA Yuet Hung Camilla Lau, Northwestern Polytechnic University, USA Huang-Chia Hung, National Taitung University Taiwan Fang-Chun Wei, Taichung Veterans General Hospital, Taiwan

\begin{abstract}
The Role of the CEO, Executive Team, and Workforce Metrics of a small University in the U.S. is not just a question of academic standards. The 21st century requirements of education involve a wider set of attributes, equipping the young with social and organizational skills to cope with adult life inside and outside the workplace (Barber, 2001). It is necessary to describe the importance of aligning clear strategic priorities with workforce metric of a small university in the U.S. In addition, effective strategy execution requires a new partnership between the CEO, the workforce, and a small university's HR function. Therefore, providing insights into the execution challenge, with examples of how a small university has developed workforce and HR strategies to drive strategy execution efforts, and offering suggestions about workforce metrics might enhance the success in strategy execution.
\end{abstract}

Keywords: American Education; Small Universities

\section{INTRODUCTION: CHANGING ROLES}

Cording to Bradshaw (2002), it is not a secret that the face of American education is changing. Today, one-third of all public school students come from communities of color, and each year the nation's classrooms become more diverse. Within 20 years, people of color will make up nearly $50 \%$ of the U.S. population and in many communities, "minorities" will become the new majority.

\section{The Changing Face of American Education}

It is critical that teachers and those who shape America's education systems reflect the students and communities they serve. When students and educational role models share a racial and cultural heritage, students begin to see the possibilities that await them, not the barriers. Traditionally underrepresented students have a better chance of achieving academically when they see people, like themselves, succeeding personally and professionally. Such role models influence young people directly, in the classroom, and indirectly, as living proof that the proverbial "American Dream" is not out of reach for people of color (Bradshaw, 2002).

The whole concept of the classroom is changing. Teachers in one school are able to teach pupils in others through broadband and whiteboard technology. Students are able to pursue investigations into, for example, medical ethics by contacting academic experts in the field directly by email. Interactive video conferencing enables students to work collaboratively with their peers in other countries. Computer programmes can provide individual tuition, rapid feedback and positive reinforcement for pupils working alone. Specialist language teaching becomes economical and tests and examinations, increasingly computer-based, can become much more imaginative and provided just in time, rather than only at set times of year (Barber, 2001). 


\section{Business and Schools in the Twenty-First Century}

Barber (2001) also mentioned that the challenge for the 21 st century is to make success a reality for all. This demands that educators believe in the possibility of high standards for every student and that policies are designed to deliver this outcome across entire education systems. A combination of new technology and new knowledge is the key to individualization and high standards for all, but will require new teaching methods to make the best use of it.

\section{Issues in Small Universities}

According to Samson, Bekessy, and Clarkson (2007), many high-level commitments to sustainability have been made by universities in the last decade, but it has become clear that universities, in general, have had a very low-success rate in translating these promises into reality. It is widely acknowledged that support and leadership by university executives and administration at the highest level is essential to achieve sustainability in mainstream practice. It is also widely known that this leadership has failed to materialize in most universities. Some researchers have suggested that "in the absence of strong administrative leadership, proponents of sustainability need to develop strategies that do not assume a top-down approach" (Thompson \& Green, 2005). Others state that organic, flexible strategies, rather than strategic plans, will succeed due to the organizational characteristics of universities (Sharp, 2002).

\section{Toward Better Schools}

It will simply not be possible for governments to provide all the necessary services for successful education systems in the next few years. New partnerships beyond the school system will be needed. The business sector, traditionally one of the main "consumers" of the "products" of the education system, will increasingly become a partner as an investor and provider of services in education. The explosion of the Internet and other new technologies demands investment in new software products. Businesses, not governments, will largely make that investment. As barber (2001) described, the rate at which computers become obsolete presents a funding challenge which governments, on their own, will not be able to solve. Maintaining and developing a stock of school buildings fit for the new century will demand huge capital expenditure. Moreover, in the competitive global market, access to highly educated staff will become ever more crucial. The question will not be whether there is business sector involvement, but on what terms.

\section{Accountability as A Capability}

Accountability and continuous professional development are only the beginning. The technological revolution that has transformed so many sectors of the economy will shortly reach critical mass in education systems. Steady investment in hardware in many countries will increasingly be matched by investment in connectivity, system maintenance and teachers' skills in the use of information and communications technology (ICT). Business investment in educational software is also rapidly growing. Furthermore, in the last two decades, there has been huge growth in our understanding of the human brain and how people learn. This combination of new technology and new knowledge is the key to individualization and high standards for all, but will require new teaching methods to make the best use of it.

\section{THE STRATEGY EXECUTION PROCESS}

A major challenge of strategy execution is to ensure that a small university has a workforce strategy and mandate leadership accountability for the success of the workforce in delivering academic results. This is a shared responsibility among the CEO, the executive team, faculty, and staff. Strategy execution requires strategy clarity and accountability by leadership and the workforce to ensure that the strategy becomes a reality. 


\section{Expectations of the CEO and the Executive Team of A Small University}

The expectations of the CEO of a small university are similar to the CEO of a small business. The CEO has specific responsibilities that are essential for the direction and focus of a small university. That is, the CEO and the executive team must decide the strategy of the school, the academic process, and how the school and its students are to be represented in the education system. From these, the school's culture needs to be determined. For instance, an operational excellence strategy, where school attempts to eliminate all process variance, requires a much more rigid approach to the faculty as opposed to the approach required by the staff within the school. In other words, effectively managing strategy execution requires a careful balance of these core and differentiated dimensions of school culture.

The CEO and the executive team of a small school also need to consider the responsibility and accountability requirement of faculty and staff at all levels for implementing the school's strategy. The accountability of the faculty function also must be clarified and specific expectations created by the CEO whereby the school board, as well as the staff function, can be held accountable for the delivery of the workforce by making the school's workforce strategy operational through faculty and executives.

\section{Expectations of Workforce Metrics of A Small School in the U.S.}

According to an April 2001 report, Preparing a New Breed of School Principals: It's Time for Action, the Southern Regional Education Board (SREB) proposed actions that every state and every school district can take to secure an ample supply of highly qualified principals. To cultivate successful principals, this report defines six strategies that state and local leaders can use to achieve that result. To compile these six strategies, SREB drew from research and - most importantly - from direct experiences in helping schools, universities and state agencies rethink and redesign educational leadership programs (Bottoms, O’Neil, Fry, \& Hill, 2003).

\section{Strategy 1 - Single out high-performers}

Stop relying on the questionable pool of "self-selected" people with administrative credentials but little inclination or talent for leadership. Instead, develop criteria and methods to choose high-quality candidates for leadership preparation. Tap those with a demonstrated knowledge of curriculum and instruction as well as a passion for helping students meet high standards.

\section{Strategy 2 - Recalibrate preparation programs}

Redesign leadership preparation programs to emphasize the core functions of the high-achieving school: curriculum, instruction and student achievement.

\section{Strategy 3 -Emphasize real-world training}

Make field-based experiences a high priority and a central focus of principal preparation programs.

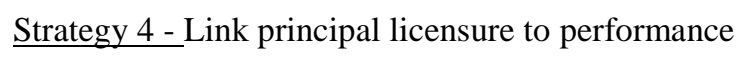

Create a two-tier licensure system for school principals. Initial licensure candidates would have to complete a preparation program focused on the core functions of successful schools. Within a specified time, those with initial licenses would have to earn professional licenses by demonstrating that they can lead improvements in school and classroom practices and in student achievement.

Strategy 5 -Move accomplished teachers into school leadership positions

Create an alternative certification program that provides a high level of support for accomplished teachers who are interested in becoming principals. This program would enable them to bypass traditional preparation and to prove themselves on the job. Limit participation in such programs to teachers with master's degrees, demonstrated leadership skills and proven records of increasing student achievement. 
Strategy 6 -Use state academies to cultivate leadership teams in middle-tier schools

Schools that rely on leadership teams, rather than on single-leader models, are most likely to improve student learning and "grow" future principals. Create state leadership academies that will cultivate school-based leadership teams and will help these leaders develop the skills and knowledge to promote effective practices that will raise student achievement. Concentrate on serving middle-tier schools, which have lagging academic performance but rarely qualify for special assistance from state and federal programs.

\section{EXPECTATION TEAM OF UNIVERSITY}

\section{1. $\quad$ Organization Structure}

Board of Director, CEO (Chief Executive Officer), CFO (Chief Financial Officer), Chair of Committee, Dean, Standard affair, Academic affair (Registration/Curriculum), General affair (Accounting department)

\section{2. $\quad$ Task Assignments}

Recruitment Affairs, International Cooperation, Research \& development, Administration Office.

\section{ESSENTIAL ROLES FOR EXECUTING WORKFORCE STRATEGY}

\section{The Role of CEO and Executive Team}

Three specific strategies that an effective CEO and executive team employ in schools that are increasing student learning are: 1) modeling learning, 2) providing compelling reasons for others to learn, and 3) creating a coaching environment for continuous growth (Barkely, Bottoms, Feagin, \& Clark, 2001).

\section{Strategy 1 -Modeling learning}

"Modeling the model" (leaders' exhibiting the behavior that they want teachers to display) is an essential leadership phrase. Tom Peters' book "The Circle of Innovation" suggests that employers stop spending their time evaluating employees and instead consider quarterly "updating-your-résumé" meetings. In these sessions, employees and their manager share what they have learned and what skills they have gained during the previous quarter that show their increasing value to the organization. School board members, principals and teachers should consider updating their résumés each quarter to identify new things they have learned.

Strategy 2 - Providing compelling reasons for others to learn

Effective leaders continuously create compelling reasons for others to learn. Learning often takes great effort by the learner and most people need to see a payoff in order to put forth that effort. Teachers who have discovered the secrets of having high expectations for all students and providing them with challenging real-world learning do not have to spend time explaining to students why learning is useful. They only have to engage learners' minds in meaningful ways and stand back as the learning itself becomes the motivating force. School leaders also can encourage staff in high-level teaching by continuously reminding them about the payoff for efforts to plan and implement strategies for high expectations and challenging content.

Strategy 3 -Creating a coaching environment for continuous growth

The third element of leading for learning is creating a coaching environment that is safe, positive and supportive, in which thinking is encouraged and risk-taking is valued. On the 2000 MSW Teacher Survey, many teachers reported that they seldom were asked to reflect upon what they learned in staff development or to work together to implement and refine new strategies. Those data indicate that coaching is needed in individual schools. Similarly, many school administrators complain that they hear from the central office only when there is a problem. Developing a coaching environment at all levels requires system and school leaders to keep score on student achievement and to create a climate of continuous coaching. 


\section{SUMMARY}

Leadership not only matters; it is second only to teaching among school-related factors that affect student learning and its impact is greatest in schools with the greatest needs, according to a comprehensive review of evidence on school leadership by researchers at the Universities of Minnesota and Toronto. This report, the first in a series that seeks to establish how leadership promotes student achievement, summarizes the basics of successful leadership and sets out what leaders must do - including setting a clear vision, supporting and developing a talented staff, and building a solid organizational structure - to meet the challenge of school reform (Leithwood, Louis, Anderson, \& Wahlstrom, 2004).

\section{AUTHOR INFORMATION}

Pei-Chih Wei, Hsin Sheng College of Medical Care and Management, E-mail: weipeichih@gmail.com. Corresponding author.

Yuet Hung Camilla Lau, Northwestern Polytechnic University, E-mail: camillayhl@gmail.com.

Huang-Chia Hung, National Taitung University Taiwan. E-mail: hank628@ @otmail.com.

Fang-Chun Wei, Taichung Veterans General Hospital, Taiwan

\section{REFERENCES}

1. Bradshaw, G. W. (2002). The changing face of American education. USA Today, 131(2688), 34-35.

2. Barber, M. (2001). Teaching for tomorrow. Organization for economic cooperation and development. The OECD Observer. 255, 11-13.

3. Barkely, S., Bottoms, G., Feagin, C. H., \& Clark, S. (2001). Leadership Matters: Building Leadership Capacity. Retrieved August 25, 2007 from http://www.wallacefoundation.org/NR/rdonlyres/6EDB66BA884F-4E70-93BB-3C90485D0238/0/LeadershipMatters.pdf

4. $\quad$ Bottoms, G., O’Neil, K., Fry, B., \& Hill, D. (2003). Good Principals Are The Key to Successful Schools: Six Strategies to Prepare More Good Principals. Retrieved August 25, 2007, from http://www.wallacefoundation.org/NR/rdonlyres/58855971-C668-448C-B938D21533E5CB43/0/GoodPrincipalsAretheKey.pdf

5. Huselid, M. A., Becker, B. E., \& Beatty, R. W. (2005). The workforce scorecard. Massachusetts: Harvard Business School.

6. Leithwood, K., Lousi, S. K., Anderson, S., \& Wahlstrom, K. (2004) How leadership influences student learning. Retrieved August 25, 2007, from http://www.wallacefoundation.org/NR/rdonlyres/E3BCCFA5A88B-45D3-8E27-B973732283C9/0/ReviewofResearchLearningFromLeadership.pdf

7. Samson, K., Bekessy, S.A., \& Clarkson, R.E. (2007). The failure of non-binding declarations to achieve university sustainability; A need for accountability. International Journal of Sustainability in Higher Education, 8(3), 301-316.

8. Sharp, L. (2002), Green Campuses: the road from little victories to systemic transformation. International Journal of Sustainability in Higher Education, 3 (2), 128-45.

9. Thompson, R., \& Green, W. (2005). When sustainability is not a priority: an analysis of trend and strategies. International Journal of Sustainability in Higher Education, 6, 7-17. 
NOTES 